\title{
Posterior Trans-Dural Repair of Iatrogenic Spinal Cord Herniation after Resection of Ossification of Posterior Longitudinal Ligament
}

\author{
Seung-Jae Hyun, Hong-Ki Kim, Ki-Jeong Kim, Tae-Ahn Jahng, Hyun-Jib Kim \\ Department of Neurosurgery, Spine Center, Seoul National University Bundang Hospital, \\ Seoul National University College of Medicine, Seongnam, Korea
}

latrogenic spinal cord herniation is a rare complication following spinal surgery. We introduce a posterior trans-dural repair technique used in a case of thoracic spinal cord herniation through a ventral dural defect following resection of ossification of the posterior longitudinal ligament (OPLL) in the cervicothoracic spine. A 51-year-old female was suffering from paraplegia after laminectomy alone for cervicothoracic OPLL. Magnetic resonance imaging revealed a severely compressed spinal cord with pseudomeningocele identified postoperatively. Cerebrospinal fluid leak and iatrogenic spinal cord herniation persisted despite several operations with duroplasty and sealing agent. Finally, the problems were treated by repair of the ventral dural defect with posterior trans-dural duroplasty. Several months after surgery, the patient could walk independently. This surgical technique can be applied to treat ventral dural defect and spinal cord herniation.

Keywords: latrogenic spinal cord herniation; Duroplasty; Cervicothoracic junction; Ossification of the posterior longitudinal ligament

\section{Introduction}

Pseudomeningoceles are extravasated collections of extradural cerebrospinal fluid (CSF) that result from a dural tear $[1,2]$. They may be traumatic, congenital and iatrogenic. Iatrogenic spinal cord herniation occurs after durotomy, usually during cervical or lumbar surgery. Extradural herniation of the thoracic spinal cord is a rare complication that presents with progressive paraplegia. After surgical reduction of the herniated spinal cord and dural repair, a patient's neurological function can be recovered [3]. In this report, we describe a case of thoracic spinal cord herniation through a ventral dural defect following resection of ossification of the posterior longitudi- nal ligament (OPLL) in the cervicothoracic spine.

\section{Technical Note}

A 51-year-old female was referred to our institute for paraplegia and anesthesia below the T2 dermatome. Deep tendon reflex was increased at knee and ankle jerk, with ankle clonus. Cervicothoracic OPLL had been diagnosed and resected with laminectomy at another hospital one week before. CSF leaked out through the surgical wound. Magnetic resonance imaging (MRI) revealed a severely compressed spinal cord and postoperative pseudomeningocele were identified (Fig. 1). We decided to revise the surgical site for neural decompression and stabilization.

\footnotetext{
Received Aug 11, 2015; Revised Sep 21, 2015; Accepted Sep 24, 2015

Corresponding author: Seung-Jae Hyun

Department of Neurosurgery, Spine Center, Seoul National University Bundang Hospital,

Seoul National University College of Medicine, 82 Gumi-ro 173 Beon-Gil, Bundang, Seongnam 13620, Korea

Tel: +82-31-787-7164, Fax: +82-31-787-4097, E-mail: hyunsj@snu.ac.kr
} 


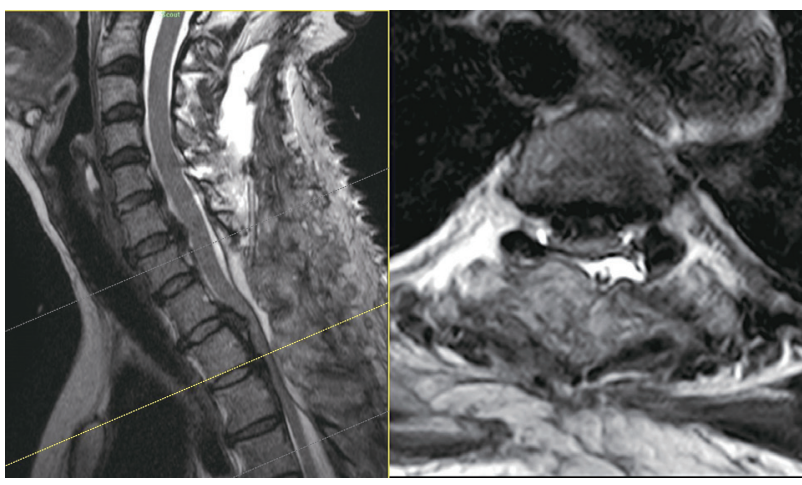

Fig. 1. Magnetic resonance imaging showing severely compressed spinal cord and postoperative pseudomeningocele.
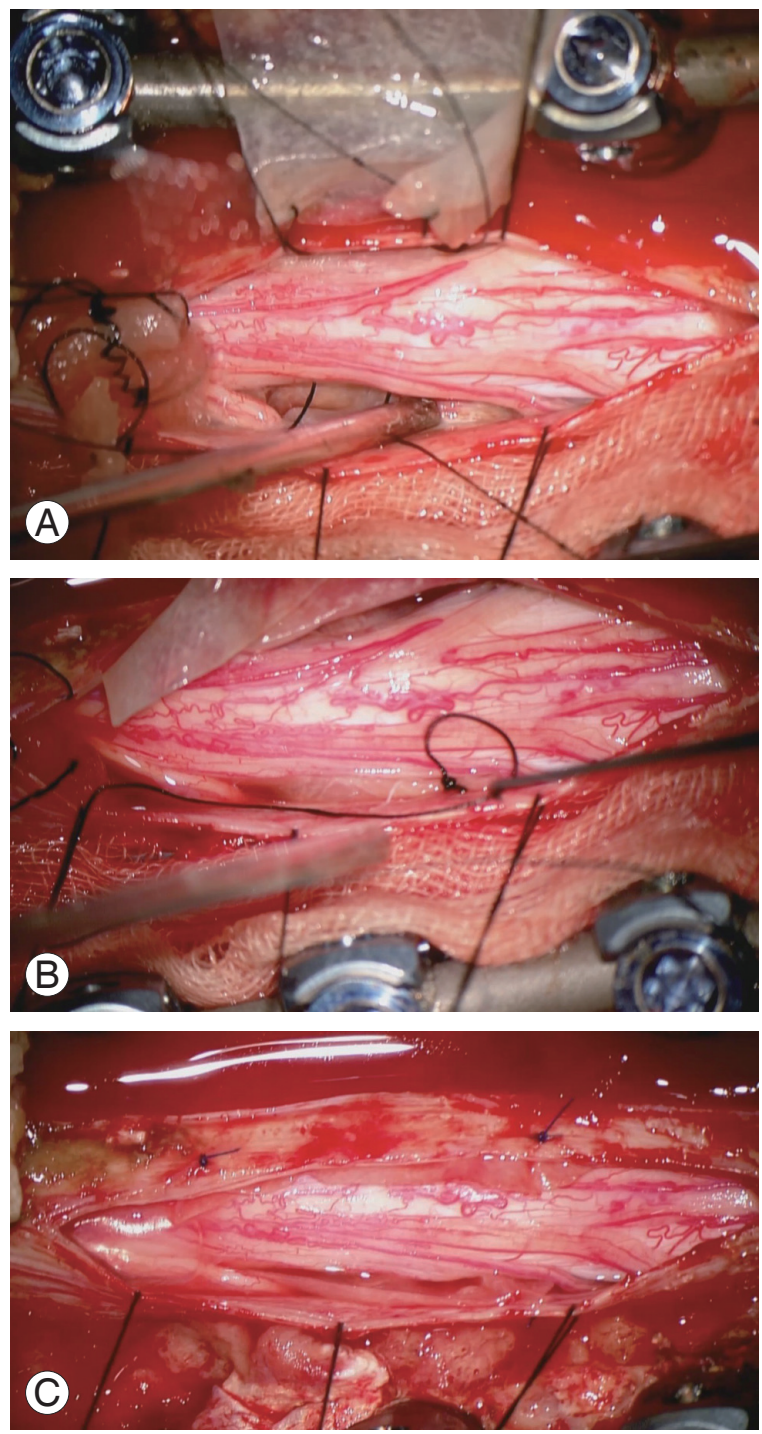

Fig. 2. Intraoperative photography: posterior trans-dural duroplasty technique. (A, B, C) An artificial dura was passed on the ventral side of the spinal cord and reinforced to the dura located on superior aspects of the upper and lower roots, allowing function as a check valve.

\section{Operation}

Through a posterior approach, we first installed pedicle screws and placed a tentative rod with dekyphotic rod contouring. After further laminectomy of the thoracic spine, severely compressed ventral dura and CSF leak from the ventral dural defect were visualized. Severe adhesion between the OPLL and ventral dura made it impossible to dissect and repair the defect primarily. We were obliged to perform duroplasty using artificial dura, muscle patch and sealant. Postoperatively, the patients' neurological status improved, but it sequentially deteriorated after 3 days. Although we performed re-operation using a similar surgical technique on day 5 after the initial operation, CSF leakage and iatrogenic spinal cord herniation with paraparesis (motor grade 2-3) persisted. Finally, the problems were treated by repair of the ventral dural defect with posterior trans-dural duroplasty on day 10 after the initial operation. The spinal cord was exposed by durotomy. To free the spinal cord, the dentate ligament was resected. The ventral OPLL was carefully resected with the attached portion of the ventral dura. The primary repair of the ventral dural defect was not feasible due to severe adhesion between the ventral dura and remained OPLL. An artificial dura was passed on the ventral side of the spinal cord and reinforced to the dura located on the superior aspects of the upper and lower roots, allowing it to function as a check valve (Figs. 2, 3). To prevent anteri-

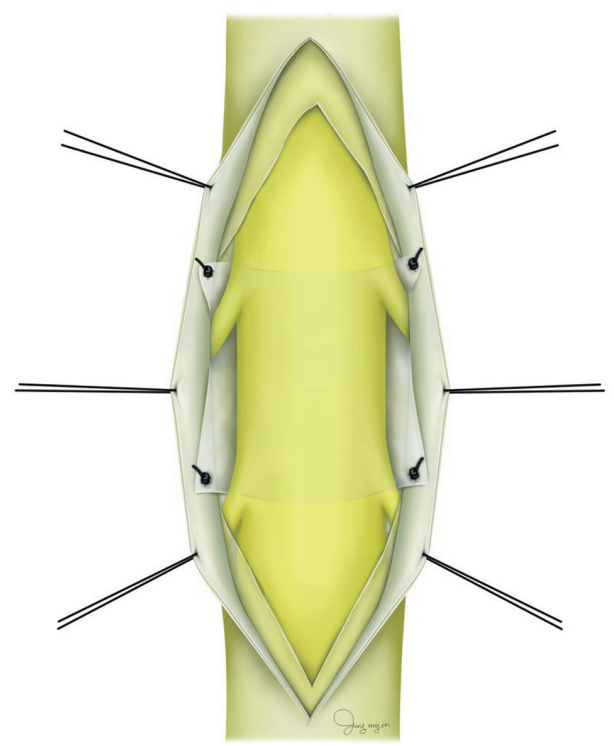

Fig. 3. Schematic drawing of the posterior trans-dural duroplasty in the shape of a check valve. 
or spinal artery injury or cord damage, careful dissection between the spinal cord and ventral dura and soft artificial dura material are mandatory.

\section{Postoperative course}

After surgery, the patient gradually recovered from paraplegia. An external orthosis was applied for 3 months to achieve bony fusion. Several months after surgery, the patient could walk independently. Postoperative MRI showed well-decompressed spinal cord without pseudomeningocele or spinal cord herniation (Fig. 4).

\section{Discussion}

Laminectomy without instrumentation has not been recommended for thoracic OPLL because of the kyphotic curvature. Dorsal shift of the spinal cord in the thoracic spine may not occur by laminectomy alone. When deciding a posterior approach, neural decompression with instrumentation should be considered [4-7].

Iatrogenic spinal cord herniation through a dural defect is a rare complication. The first report of iatrogenic spinal cord herniation was published over 40 years ago [3]. A meta-analysis of 126 case reports indicated the several cases with ventral thoracic dural defect [8]. However, no cases of spinal cord herniation following resection of
OPLL in the thoracic spine have been reported.

A previous clinical study involving a series of patinets with idiopathic spinal cord herniation determined that the most common clinical symptom was Brown-Sequard syndrome [9]. The authors suggested the symptoms might be derived from the involvement of the anterolateral funiculus. On the other hand, another investigator explained the symptoms as myeloradiculopathies [10].

In this case, recurrence of iatrogenic spinal cord herniation even after repeat revision surgery is thought to have worsen the neurological symptoms. Despite advancements in surgical techniques for thoracic OPLL, favorable results are not always achieved. In patients with thoracic myelopathy resulting from thoracic OPLL, removal of the ossified PLL is the most effective method of relieving pressure on the spinal cord [7,11-15]. A surgical technique for OPLL of the thoracic spine which was removed by floating method has been described [16]. For this patient, floating method was not feasible because of extensive adhesion between the dura and OPLL.

Direct primary closure of ventral dural defect is the best way to treat spinal cord herniation [17]. However, primary closure is not always feasible. A previous study reported that a muscle pedicle flap technique to repair a CSF fistula can be used as an alternative to the direct closure of ventral dural defects [18]. The authors suggested that the technique can be used as an alternative to the
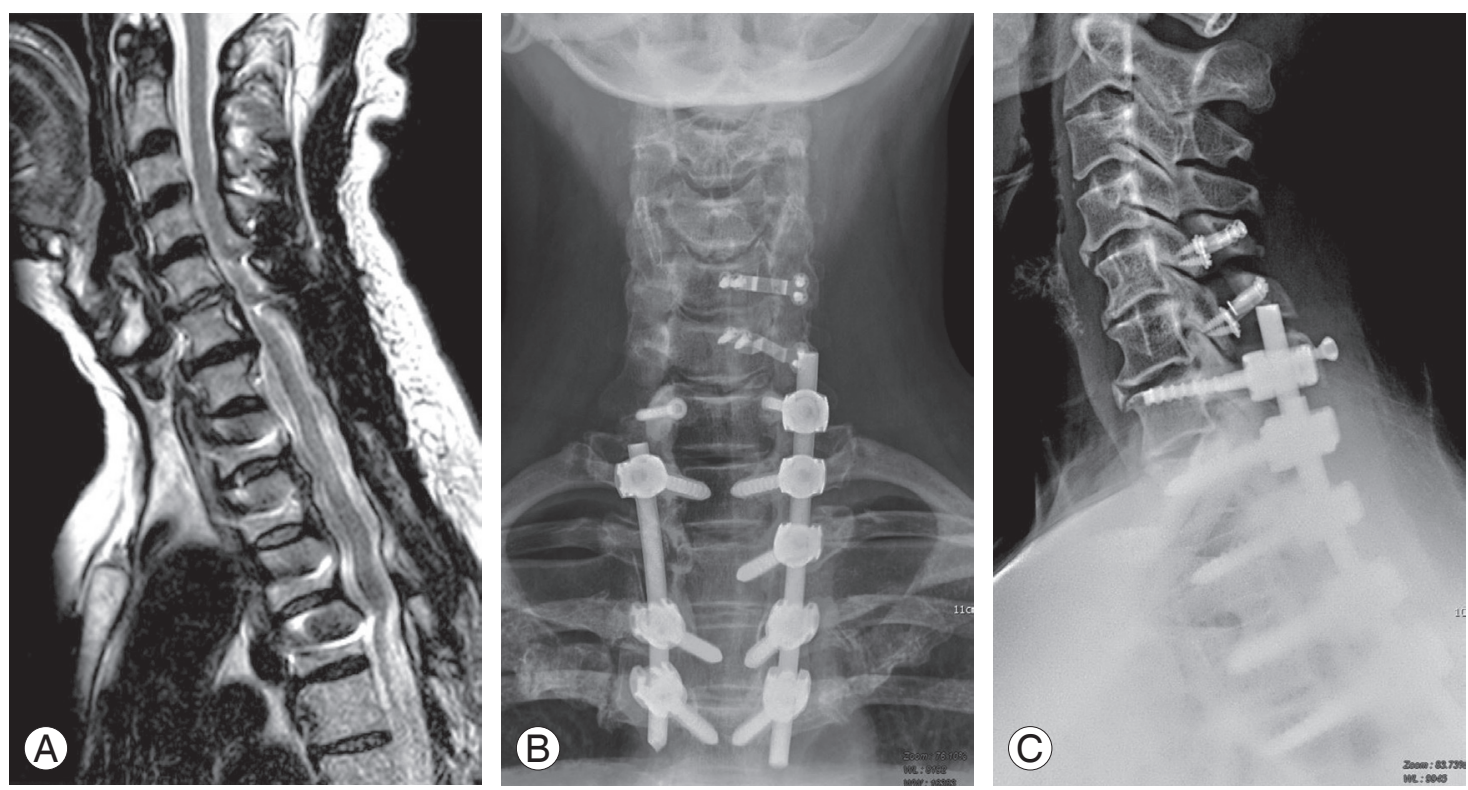

Fig. 4. (A) Magnetic resonance imaging showing well-decompressed spinal cord without pseudomeningocele or spinal cord herniation. (B, C) postoperative $\mathrm{X}$-ray shows dekyphosis of cervicothoracic junction by instrumentation. 
direct "water-tight" closure of ventral cervical dural defects. A trans-dural duroplasty technique utilizing GoreTex through a trans-dural approach has been detailed [8]. However, the method is less effective in preventing the large dural defect. A recent paper reported a case of posterior cord reduction and dural repair after multilevel anterior thoracic vertebrectomy for a giant cell tumor [19]. The authors closed the ventral dural defect using an artificial dura anteriorly to the cord. The edges of the artificial dura were inside the spinal dural edge, entirely covering the defect in an inside-out fashion. However, surgical details or drawings were not presented.

Repair of the ventral dura is an important step of our surgical method with a duroplasty in the shape of a check valve, making it possible to prevent CSF leakage if direct primary closure is not feasible. Sophisticated care should be taken to prevent anterior spinal artery injury or cord damage, when passing the artificial dura beneath the spinal cord.

Duroplasty in the shape of a check valve through posterior trans-dural approach for iatrogenic spinal cord herniation is described. This surgical method for dural repair can serve as an option in patients with ventral dural defect and iatrogenic spinal cord herniation if direct primary closure is not feasible.

\section{Conflict of Interest}

No potential conflict of interest relevant to this article was reported.

\section{Acknowledgments}

We appreciate the assistance of Mijin Jung, the artist who drew Fig. 3 in this manuscript. She worked as a medical illustrator for the Department of Neurosurgery, Baylor College of Medicine from 2009 to 2011, and has worked in the Department of Neurosurgery, Seoul National University Bundang Hospital, Seoul National University College of Medicine since 2013.

\section{References}

1. Hawk MW, Kim KD. Review of spinal pseudomeningoceles and cerebrospinal fluid fistulas. Neurosurg Focus 2000;9:e5.

2. Macki M, Lo SF, Bydon M, Kaloostian P, Bydon A.
Post-surgical thoracic pseudomeningocele causing spinal cord compression. J Clin Neurosci 2014;21: 367-72.

3. Cobb C 3rd, Ehni G. Herniation of the spinal cord into an iatrogenic meningocele. Case report. J Neurosurg 1973;39:533-6.

4. Matsumoto M, Toyama Y, Chikuda H, et al. Outcomes of fusion surgery for ossification of the posterior longitudinal ligament of the thoracic spine: a multicenter retrospective survey: clinical article. J Neurosurg Spine 2011;15:380-5.

5. Yamazaki M, Okawa A, Fujiyoshi T, Furuya T, Koda M. Posterior decompression with instrumented fusion for thoracic myelopathy caused by ossification of the posterior longitudinal ligament. Eur Spine J 2010; 19:691-8.

6. Matsuyama Y, Sakai Y, Katayama Y, et al. Indirect posterior decompression with corrective fusion for ossification of the posterior longitudinal ligament of the thoracic spine: is it possible to predict the surgical results? Eur Spine J 2009;18:943-8.

7. Fujimura Y, Nishi Y, Nakamura M, Toyama Y, Suzuki N. Long-term follow-up study of anterior decompression and fusion for thoracic myelopathy resulting from ossification of the posterior longitudinal ligament. Spine (Phila Pa 1976) 1997;22:305-11.

8. Groen RJ, Middel B, Meilof JF, et al. Operative treatment of anterior thoracic spinal cord herniation: three new cases and an individual patient data meta-analysis of 126 case reports. Neurosurgery 2009;64:ons145-59.

9. Najjar MW, Baeesa SS, Lingawi SS. Idiopathic spinal cord herniation: a new theory of pathogenesis. Surg Neurol 2004;62:161-70.

10. Watters MR, Stears JC, Osborn AG, et al. Transdural spinal cord herniation: imaging and clinical spectra. AJNR Am J Neuroradiol 1998;19:1337-44.

11. Hyun SJ, Kim JS, Hong SC. Late occurrence of cervicothoracic ossification of posterior longitudinal ligaments in a surgically treated thoracic OPLL patient. J Korean Neurosurg Soc 2010;47:55-7.

12. Ido K, Shimizu K, Nakayama Y, et al. Anterior decompression and fusion for ossification of posterior longitudinal ligament in the thoracic spine. J Spinal Disord 1995;8:317-23.

13. Suzuki R, Ohno K, Inaba Y. Fracture of the floor of the anterior cranial fossa and the sella turcica, and 
successful repair of the cerebrospinal fluid fistula with fibrin glue: case report. Neurol Med Chir (Tokyo) 1986;26:420-5.

14. Tomita K, Kawahara N, Baba H, Kikuchi Y, Nishimura H. Circumspinal decompression for thoracic myelopathy due to combined ossification of the posterior longitudinal ligament and ligamentum flavum. Spine (Phila Pa 1976) 1990;15:1114-20.

15. Tsuzuki N, Hirabayashi S, Abe R, Saiki K. Staged spinal cord decompression through posterior approach for thoracic myelopathy caused by ossification of posterior longitudinal ligament. Spine (Phila Pa 1976) 2001;26:1623-30.

16. Kato S, Murakami H, Demura S, Yoshioka K, Hayashi $\mathrm{H}$, Tsuchiya $\mathrm{H}$. Novel surgical technique for os- sification of posterior longitudinal ligament in the thoracic spine. J Neurosurg Spine 2012;17:525-9.

17. Aydin AL, Sasani M, Erhan B, Sasani H, Ozcan S, Ozer AF. Idiopathic spinal cord herniation at two separate zones of the thoracic spine: the first reported case and literature review. Spine J 2011;11:e9-e14.

18. Hyun SJ, Rhim SC, Ra YS. Repair of a cerebrospinal fluid fistula using a muscle pedicle flap: technical case report. Neurosurgery 2009;65:E1214-5.

19. Kawsar KA, Bhatia R, Casey AC. Spinal cord herniation as a complication of en bloc, multilevel, anterior thoracic vertebrectomy for a giant cell tumor: success of posterior cord reduction and dural repair. J Neurosurg Spine 2014;21:909-12. 